\title{
A case for psychology as a human science
}

\begin{abstract}
The disciples of Psychology and Sociology and the social sciences more generally, are and have been for some time, in a state of flux, especially with regard to research methods. The tension, in the view if many, is between the approaches to research in terms of positivist verses naturalist. ${ }^{1,2}$ This tension has to a considerable degree remains unsolved and has been exacerbated by the postmodernist's discourse as exemplified in the works of Foucault ${ }^{3}$ and Lyotard $^{4}$ (see Rosenberg, 2003 for an overview of this discourse). This short commentary cannot address all of these issues. Instead, it will ${ }^{5}$ provide an introduction to the history of 19 th century and early 20th century social sciences focusing on key differences and similarities in research methods and their philosophic underpinning. ${ }^{6}$ This will be followed by a short statement regarding the nature of mid 20th century evolution of the social sciences, touching on both the philosophical and practical aspects of research. ${ }^{7}$ This essay will end with an overview of some psychology research conducted within the parameters of the Human sciences.
\end{abstract}

Keywords: jerome bruner, john dewy, gh mead, shawn Rosenberg, michael westerman, peter wench, cultural psychology, social psychology, psychological anthropology, meaning; narrative, mind, culture
Volume 2 Issue 6 - 2015

\section{Richard Morehouse}

Viterbo University, School of Education and Community,

Glyndwr University, USA

Correspondence: Richard Morehouse, I3 | Charles Street Praxis, La Crosse, WI 54603 II 5 5th Avenue South, USA, Tel (608) 784-5707, Email remorehouse@viterbo.edu

Received: May 07, 2014 | Published: May 12, 2015

\section{Introduction}

The Natural Sciences and the Human Sciences have different aims. The human sciences seek to understand actions and relationships while the natural sciences, according to Dilthey, ${ }^{8}$ seek to control nature. Methods of inquiry are at the core of what a science is. Inquiry methods are what define the sciences. George Herbert Mead ${ }^{9}$ and Winch ${ }^{10}$ continued Dilthey's ${ }^{8}$ articulation of a contemporary understanding of methods in the human sciences. Winch argues that predictions in the natural sciences, where a "falsified prediction always implies some sort of mistake on the part of the predictor; false or inadequate data, faulty calculation, or defective theory" whereas in the human sciences the whole point about "a decision is that a given set of 'calculations' may lead to any one of a set of different outcomes". ${ }^{10}$ The goal of falsifying predictions versus understanding that research might lead to a set of different outcomes is a major difference between the natural sciences and the human sciences.

As science, in the common discourse, is nearly synonymous with what I have called natural science and as psychology sees itself as a science, I will make only a brief case for psychology as a natural science. Wilhelm Wundt's lab and the subsequent publication of his journal, Philosophische Studien (1883) marked psychology as an independent field of study. Psychology, since the time of Wundt's first psychology lab founded in 1879 at University of Leipzig, has been considered almost exclusively an experimental science. The experimental version of psychology is the one that was initially adopted in the United States psychology community. The adoption of the experimental approach to psychology on the USA is often attributed to Edward Titchener's translation of the experimental work of Wilhelm Wundt ${ }^{11}$ and the lack of translation of his social or folk psychology theories and research.

Psychology as a natural science continued to dominate university based study and research. Initially the research method was introspection, but this approach was replaced by behaviorism (Pavlov, Watson, \& Skinner). Much experimental work was concerned within learning theory based in reinforcement and contingency. According to Skinner $\mathrm{BF}^{12}$ what was inside the learner was not measurable and therefore not knowable. Skinner's ${ }^{12}$ "black box" theory of behavior argues that experimental analysis of behaviors indicate that all behavior is the result of environmental stimuli. By the middle of the twentieth Century, this "black box" theory of learning was changed by a new look at perception. ${ }^{13}$ The shift also included an orientation toward the social construction of reality. ${ }^{14}$ The use of computer programming provided another way to look inside the "black box". The programming of computers and the ways programs in some ways mimic human thinking within the limits of an if-then framework ${ }^{15}$ provided a unique look inside this so called "black box"".

However, the definition and methods of the new discipline of psychology was more fluid than it might appear in the standard history of science (cf. Schultz \& Schultz, for the standard or traditional telling of this history). Somewhat earlier, Wilhelm Dilthey, a contemporary of Wundt, published Introduction to the human sciences: an attempt to lay a foundation for the study of society and history published in 1888. At about the same time, Sigmund Freud having studied philosophy under Franz Brentano and physiology under Ernst Brücke, explores another approach to understanding human experiences as articulated in The Interpretation of Dreams(1900). Another of Wundt's other major works was Volkerpsychologie (1904) The English translated of Volkerpsychologie was 12years later translated into English and was first available in London in 1916 as Elements of Folk Psychology. The early work of John Dewey ${ }^{16}$ and James Mark Baldwin ${ }^{17}$ also provide an alternate perspective on the dominance of a natural science view of Psychology.

\section{A case for psychology as a human science}

In order to make an applied case of a modern understanding of human science, I looked to interpretive methods of inquiry as key components of those sciences. Jerome Bruner ${ }^{13}$ pioneered many of these methods beginning with his early work on perception. Bruner, ${ }^{13}$ along with colleagues and students, initiated a series of experiments that led to an orientation to what some called the 'New Look' psychology. ${ }^{18}$ These studies helped to move psychology away from a strict behavioral perspective that dominated psychological research at the time. Cognitive psychology during the 1970s and up to the current time has moved to a computational or information processing approach to research. Bruner ${ }^{19,20}$ and others have recently been working to reclaim a more humanistic psychology, that is, psychology as a human science. 
Bruner's ${ }^{18}$ work at Oxford University on language continued his human sciences efforts (1983). A social construction theory of meaning in which individuals and groups create shared meaning was at the center of his research. Actual minds, possible worlds ${ }^{19}$ extend this approach as he worked to develop a narrative theory of understanding. Actual Minds, Possible Worlds is the most influential work in Psychology for the Twenty-First Century, if the number of citations is the criteria for influences. That work has been cited in over 16,100 scholarly publications. Bruner ${ }^{20}$ extends his thinking on narrative to make a case for understanding human interaction more generally in Acts of meaning (1990).

The human sciences, in this view, are situated between two poles. At one end is behaviorism and information processing/computational understanding of persons and at the other end is biopsychology or neuropsychology considered narrowly. Psychology as a human science is characterized by the way it attempts to understand humans. John Dewey, ${ }^{21}$ a near contemporary of Dilthey, ${ }^{8}$ argues for an alternate approach to psychological research as early as 1896 in his article "The reflex arch concept in psychology". Both Dilthey ${ }^{8}$ and Dewey ${ }^{21}$ take an anti-Cartesian position on the nature of humans as knower's and as the subject of knowing. Key to this approach is the necessity of negotiation. Negotiation is what makes "interpretation and meaning central" to psychology or any of the mental sciences. ${ }^{20}$

Building on the work of Dewey ${ }^{16,21}$ and Dilthey, ${ }^{8}$ both implicitly and explicitly, Bruner ${ }^{20}$ argues for an approach to research that is humanistic and scientific. His interpretative framework for research has three core features: agency, action and meaning making. Also contributing to the framework and content of this commentary are key works from Bandura $\mathrm{A}^{6}$ and Michael Westerman 22 to name only the most relevant scholars who informed this orientation to understanding humans. The work of these scholars provides the framework on which I build my orientation to inquiry.

Below is an overview of the core features of interpretative research as a human science. An interpretative research project in this view is based on agency, action and meaning making. Agency, action and meaning making are closely related concepts. ${ }^{2}$ I will separate them in an effort to highlight the most salient features of each, while recognizing the interactions of the three components. Agency is co-equal with action and meaning making as important features that are intended not only to provide an orientation to the specifics of conducting a research project but also a partial definition of psychology as a human science. In like manner, meaning making may be seen as the goal of agents. The three elements are conceptual tools intended to aid in the construction of a review of the literature and more generally a framework for understanding and critiquing other research.

Agency is the first core feature presented here. While the etymology of agency points to action as the origin of the word, action in modern use is not the same as agency. Agency focuses on the actor and action focuses on the doing of some behavior. Acts of meaningby Jerome Bruner ${ }^{20}$ provides much of the background used as a means of understanding agency. Additional understanding and application to research comes primarily from the work of John Dewey ${ }^{21}$ and Albert Bandura. ${ }^{6}$ Below are the highlights of the four components of agency (intentionality, forethought, social reactiveness and self-reflection) as gleaned from the above authors. Agency is understood from the two points of view: that of the inquirer and the subject of the inquiry.

Agency has four key features:

i. Intentionality

\section{ii. Forethought \\ iii. Self-reactiveness \\ iv. Self-reflectiveness}

Intentionality according to Albert Bandura ${ }^{6}$ and John Dewey ${ }^{21}$ is a representation of a future course of action that one plans to perform. For an agent to accomplish something one needs a plan. Forethought is self-motivation and guides one's actions in anticipation of a future event. Self-reactiveness is the performance comparison with the personal goals and standards that direct action. Self-reflectiveness is the capacity to reflect upon oneself and the adequacies of one's thoughts and actions. When conducting and reviewing research, it is helpful to consider how each of these features affects and is affected by both the inquirer and the participant., ${ }^{2,6}$

Action is the next feature outlined. My understanding and application of the concept of action to research originates with the works of John Dewey, ${ }^{21}$ Rom Harré ${ }^{23}$ and Michael Westerman. ${ }^{22}$ Action according to these scholars is interpersonal, contextual, in progress and formed by language. Westerman ${ }^{24}$ argues that action is always between persons or things. Interaction is the focus of interpretative research. It is essential in understanding human change and development. While it may seem obvious that context is essential to understanding psychology, interaction is often glossed over, if not completely ignored in many theories of psychology, thus lessening understanding of the phenomenon. Researchers instead tend to look at completion rather than at the interaction in progress. To understand a phenomenon we need to recognize that action is also always in progress, in media res, to use Westerman's term; that is action is located in the middle of things. Strangely, this means that a phenomenon does not have an easily discernible beginning nor does the phenomenon have an ultimate endpoint. This characterization is, on the surface, paradoxical, however, a moment's reflection on our own action clarifies this point. Making a new friend is informed by past actions, the present situation and the time and place of the interaction. Also our past experience with other friends, with the person I am making friends with as well as the context in which I find myself at this moment, all influence both the making of that friend and my understanding of that relationship. The activities of making a friend are at the same time narrowly temporal and a part of a larger time oriented framework.

Importantly, Westerman ${ }^{24}$ and Harré ${ }^{23}$ both include language as a form of action such as commands, requests and petitions. Language, even when considered as mere conversation, is an essential part of understanding human action. Conversation as an act is always in a structural and temporal context. Further, Harré ${ }^{25}$ argues that language is one of the ways persons are positioned hierarchically in social and cultural situations. Understanding of how these relationships are formed and operate is a part of understanding human interaction.

The last feature of inquiry discussed here is meaning making. John Dewy, ${ }^{21}$ Matthew Lipman ${ }^{26}$ and Michael Westerman ${ }^{24}$ are the main sources of my understanding and application of the idea of meaning making to inquiry. We, as a species, are meaning makers and meaning seekers. Meaning construction follows from our being both free and constrained. ${ }^{5}$ We construct meaning within contexts. My understanding of meaning making is based on sorting out aims and ends as Dewey $^{21}$ refers to this component of inquiry. Using a different nomenclature, Matthew Lipman ${ }^{26}$ writes about part/whole relationships. This meaning making is a part of an on-going practice in search of something larger than the individual act. Our construction of meaning occurs within specific contexts, as does action discussed above. This 
meaning making happens within time and in the middle of things. Like action, it occurs in media res, but unlike action, it has an antecedent and an outcome. These three characteristics discussed above (agency, action and meaning making) define psychology as human sciences. These characteristics distinguish psychology as a human science from psychology as a biological or physical/neuropsychology. Human sciences psychology is a psychology of the mind, not a psychology of the brain. The mind and the self are different entities from the brain and the self despite what Patricia Smith Churchland ${ }^{27}$ says.

\section{Finding a place for the human sciences}

Other scholars' have approached research using a similar philosophical orientation. For example, Roy Bhaskar ${ }^{28}$ and colleagues articulate a more-or-less fully developed approach to the human sciences. Shawn Rosenberg's ${ }^{29}$ approach to human understanding specifically focuses on political/social psychology and its relationship to understanding contemporary society as interpreted and negotiated. Margret Acher, ${ }^{5}$ a colleague of Bhaskar, states succinctly what all the above theories have in common as she situates the human sciences within an understanding of what it means to be an agent and a meaning maker.

We are simultaneously free and constrained and we also have some awareness of it. The former derives from the nature of social reality; the latter from human nature's reflexivity. Together they generate authentic (if imperfect) reflection upon the human condition in society. ${ }^{10}$ It is because of the perimeters of freedom with constraints that make for the necessary conditions for a Human Sciences based Psychology. While the first parts of this commentary have outlined some of the characteristics of research in the human sciences based psychology it is the existential fact that we are both free and constrained that are central to a human sciences oriented psychology. In considering the importance of making a distinction between psychology using the tools of natural sciences rather that the tools of the human sciences, the words of Peter Winch may shed some light.

Two things may be called 'the same' or 'different' only with reference to a set of criteria which lay down what is to be regarded as relevant difference. When the 'things' in question are purely physical the criteria appealed to will of course be those of the observer. But when one is dealing with the intellectual (or indeed and any kind of social) 'things', that is not so. For their being intellectual or social, as opposed to physical, in character depends entirely on their belonging in a certain way to a system of ideas or a mode of living. It is only by reference to the criteria governing that system of ideas or mode of life that they have any existence as intellectual or social events. ${ }^{10}$

Winch is writing about two different ways of seeing the same world. His point is similar to the one express in Bruner's Actual minds, possible worlds $(1986)^{19}$ and Acts of meaning (1990).$^{20}$ The bare bones of Bruner's argument are that understanding of human persons begins with the investigation of the "concept of meaning and the processes by which meanings are created and negotiated within a community" (1990:11). A Human Sciences Psychology is based in culture. Psychology as a human science, as a system of ideas, is grounded in an approach to research that I have called interpretative inquiry. ${ }^{2}$ Research in a Human Sciences Psychology, whether experimental or qualitative or mixed methods is most helpful to researchers and consumers of research if it based in meaning making that is culturally mediated.

\section{Exemplars of human science research in psychology}

The research I have selected as exemplars of Human Sciences researchers in Psychology may appear to be somewhat arbitrary but were chosen to illustrate the breath of topics in Human Sciences Psycholo- gy as well as illustration of some of the methods of this approach. A short discussion of Bruner as Human Science psychologist as I argue that he has been working to articulate a counter narrative to main street experimental psychology at least since his work was named "the new look." His classic study Value and Need as Organizing Factors in Perception (1947) ${ }^{13}$ brought into view the role of class (i.e., rich and poor children) in their ability to estimate the size of coins or wooden disks the size of American pennies, nickels, dimes, quarters and half-dollars. His work in educational psychology and learning theory continued to focus on meaning making within a cultural context including his contributions to Head Start and the creation of his own educational curriculum Man: a course of study (1965). ${ }^{30}$ Piaget, Vygotsky and Geert $^{31}$ influenced this body of work among others. All this researchers contributed to his orientation toward research methods and theoretical construction. His work at Oxford on "motherese" (Learning the mother tongue, 1978), ${ }^{21}$ Child's talk (1983) and Narratives form the crib (1989) edited by Kaherine Nelson ${ }^{32}$ continued his work on language, meaning making and culture.

Other important contributors to a Human Sciences approach to Psychology would include Rom Harré, ${ }^{25}$ Michael Westerman, ${ }^{22,24}$ Mary Belenky ${ }^{7}$ and colleagues, Shawn Rosenberg ${ }^{29}$ and Dan McAdams. ${ }^{33}$ Harré's $\mathrm{s}^{23,25}$ work on positioning added a new perspective on the cultural perspective of Psychology. Michael Westerman ${ }^{22,24}$ makes a case, similar to the one made by john Dewey ${ }^{21}$ for a post-Cartesian qualitative study of action. Mary Belenky ${ }^{7}$ coupled with the pioneering work of William Perry ${ }^{34}$ placed learning within a cultural and historical setting, Sean Rosenberg ${ }^{29,35,36}$ argues for an present of and presents a study of modes of reasoning and the social structure of thought. Dan McAdams ${ }^{33}$ outline how personal narrative provides a look at personality. In The stories we live by, McAdams ${ }^{33}$ follows a similar path, as does Jerome Bruner ${ }^{20}$ in his ultimate chapter of Act of meaning (1990) entitled: Autobiography of the self.

Additionally, I argue that it is important to consider psychology as a human science as this approach helps to keep psychology rooted in at least one of its two main goals, that is, plausible explanation and description of the phenomena. Psychology as human science, much like anthropology, sociology and linguistics, seeks plausible explanations over causal explanations. Causal explanations may be easily artificialized beyond the point of recognition as representative of human life. ${ }^{12}$ This is because in order to make clear predictions it is necessary to eliminate all the possible variables that might influence and bias the outcomes of the study. But stripping these variables out of the study also risks stripping the life out of the research. According to this view a human sciences/interpretative inquiry psychology provides an umbrella for keeping psychology relevant.

\section{Conclusion}

I hope I have made it clear that I am not arguing against experimental work. Rather, I am arguing that all work in psychology is best conceived as interpretative inquiry based on agency, action and meaning-making as basic elements in the search for understanding humans. Even the most biologically oriented psychology has or should have a research orientation that has elements of the human sciences at its core. ${ }^{2}$

\section{Acknowledgments}

None.

\section{Conflicts of interest}

Author declares there are no conflicts of interest. 


\section{Funding}

None.

\section{References}

1. Lincoln YS, Guba EG. Naturalistic inquiry. Sage Publications, Beverly Hills, USA. 1985. p.416.

2. Morehouse RE. Beginning Interpretative Inquiry: a step-by-step guide to research and evaluation. Routledge Taylor \& Francis Group, London, UK. 2012. p.142.

3. Foucault M. The archaeology of knowledge and the discourse on language. Pantheon Books, New York, USA. 1972. p.239.

4. Lyotard JF. The postmodern condition: a report on knowledge. University of Minnesota Press, Minneapolis, USA. 1984.

5. Archer MS. Realist social theory: The morphogenetic approach Cambridge university press, UK. 1995. p.368.

6. Bandura A. Social cognitive theory: An agentic perspective. Annu Rev Psychol. 2001;52:1-26.

7. Belenky MF, Clinchy BM, Goldberger NR, et al. Women's ways of knowing: The development of self, voice, and mind. John Wiley \& Sons, Inc., USA. 1988. p.113-121.

8. Dilthey W. Introduction to the Human Sciences: An Attempt to Lay a Foundation for the Study of Society and History. Wayne State University Press, Detroit, USA. 1988.

9. Mead GH. Mind, self and society from the standpoint of a social behaviorist. University of Chicago Press, Chicago, USA. 1934.

10. Winch $P$. The idea of a social science and its relationship to philosophy (2nd edn), Routledge Taylor \& Francis Group, London, UK. 1990.
11. Wundt W. Elements of Folk Psychology: outlines of a psychological history of the development of mankind. George Allen \& Unwin, London, UK. 1916.

12. Skinner BF. Upon further reflection. Prentice-Hall, Englewood Cliffs, USA. 1987. p.105-108.

13. Bruner JS, Postman CC. Value and Need as Organizing Factors in Perception. In: Bruner JS \& Goodman CC (Eds.), Classics in the History of Psychology. Journal of Abnormal and Social Psychology. $1947 ; 42: 33-44$

14. Berger PL, Luckmann T. The Social Construction of Reality: A Treatise in the Sociology of Knowledge. Penguin Books, New York, USA. 1966. p.247.

15. Simon HA, Newell A. Human problem solving: The state of the theory in 1970. American Psychologist. 1971;26(2):145-159.

16. Dewey J. The Reflex Arc Concept in Psychology. Psychological Review. 1896;3:357-370.

17. Baldwin JM. Darwin and the Humanities (Vol. 2). Forgotten Books, London, UK. 1909. p.141.

18. Bruner JS, Postman CC. On the Perception of Incongruity: A Paradigm. Journal of Personality. 1949;18(2):206-223.

19. Bruner J. Actual minds, possible worlds. Harvard University Press, Cambridge, USA. 1987. p. 222.

20. Bruner J. Acts of meaning. Harvard University Press, C ambridge, USA. 1993. p.208.

21. Dewey J. Philosophy of education: Problems of Men. Littlefield, Adams \& Co, Totowa, New Jersey, USA. 1975. 